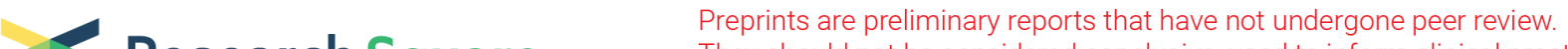 $\begin{array}{ll}\text { Research Square } & \text { They should not be considered conclusive, used to inform clinical practice, } \\ \text { or referenced by the media as validated information. }\end{array}$ \\ Prizes Signal Scientific Revolutions
}

\section{Ching Jin}

Northwestern University https://orcid.org/0000-0003-2509-4034

\section{Yifang Ma}

Southern University of Science and Technology

Brian Uzzi ( $\nabla$ uzzi@northwestern.edu )

Northwestern University https://orcid.org/0000-0001-6855-2854

\section{Article}

Keywords: scientific revolutions, scientific prize, scientific topics

Posted Date: December 10th, 2020

DOl: https://doi.org/10.21203/rs.3.rs-121409/v1

License: (c) (1) This work is licensed under a Creative Commons Attribution 4.0 International License. Read Full License

Version of Record: A version of this preprint was published at Nature Communications on October 5th, 2021. See the published version at https://doi.org/10.1038/s41467-021-25712-2. 


\title{
Prizes Signal Scientific Revolutions
}

\author{
Ching Jin ${ }^{1,2}$, Yifang $\mathrm{Ma}^{1,3}$, Brian Uzzi ${ }^{1,2^{*}}$ \\ ${ }^{1}$ Northwestern Institute on Complex Systems (NICO), Northwestern University \\ ${ }^{2}$ Kellogg School of Management, Northwestern University \\ ${ }^{3}$ Department of Statistics and Data Science, Southern University of Science and \\ Technology \\ *Corresponding Author:uzzi@northwestern.edu
}

\begin{abstract}
Scientific revolutions affect funding, investments, and technological advances, yet predicting their onset and projected size and impact remains a puzzle. We investigated a possible signal predicting a topic's revolutionary growth - its association with a scientific prize. Our analysis used original data on nearly all recognized prizes associated with 11,539 scientific topics awarded between 1960 and 2017 to examine the link between prizes and a topic's unexpected growth in productivity, impact, and talent. Using difference-in-differences regressions and counterfactuals of matched prizewinning and non-prizewinning topics, we found that in the year following the receipt of a prize, a topic experiences an onset of extraordinary growth in impact and talent that continues into the future. At between five to 10 years after the prize year, prizewinning topics are $38 \%$ more productive and $31 \%$ more impactful in citations, retain 53\% more incumbents, and gain $35 \%$ more new entrants and $46 \%$ more star scientists than their non-prizewinning peer topics. While prizewinning topics grow unexpectedly fast in talent and impact, funding does not drive growth; rather, growth is positively associated with the recency of work on the topic, discipline-specific rather than general awards, and prize money. These findings advance understanding of scientific revolutions and identify variations in prize characteristics that predict the timing and size of a topic's revolutionary growth. We discuss the implications of these findings on how funding agencies and universities make investments and scientists commit time and resources to one topic versus another, as well as on the quality of research.
\end{abstract}




\section{Introduction}

Scientific revolutions involve the unexpectedly fast growth of a scientific topic's impact and talent and have been famous throughout history for inspiring scientistic solutions to intellectual and technological challenges ${ }^{1-3}$. However, little is known about the factors predicting the genesis of a revolution ${ }^{4}$ despite the fact that knowledge about when and where revolutions occur can lead to better coordination of scientific talent and research investments ${ }^{5-7}$.

Revolutions follow the decisions of scientists to commit their resources to a topic perceived to have strong prospects for development ${ }^{4,8,9}$. However, for any single scientist, estimating a topic's prospective growth is difficult because the factors that predict a topic's growth requires extensive data collection and discerning analysis ${ }^{10-16}$. Under such conditions of uncertainty and costly direct measurement, scientists frequently make decisions using signals ${ }^{6,17-19}$. For example, journal ranking is taken as a signal of a paper's true quality ${ }^{17,20,21}$, order of authorship is taken as a signal of how much credit an author deserves on a paper ${ }^{17,22}$, and educational pedigree is taken by hiring committees as a signal of a candidate's fundamental abilities ${ }^{8,21}$.

We investigated a signal that scientists possibly follow to anticipate a scientific topic's future extraordinary growth - a topic's association with a scientific prize ${ }^{23-30}$. Scientific prizes appear to play many roles in advancing science but are only now becoming a focus of theoretical and empirical study that suggests they may be associated with more than the recognition of individual achievement. Recent work on scientific prizes has revealed that prizes have proliferated in modern science and can inspire risk-taking, highlight overlooked ideas, and involve public rituals that reinforce norms of good scientific practice ${ }^{24,31-35}$. Our work builds on research that shows that prizes can change perceptions of a scientist's work ${ }^{23,34}$. Analyses of the Howard Hughes Medical Investigator prize shows that awardees' past papers gain more citations than expected ${ }^{28}$, while nonprizewinners' citations decline ${ }^{36}$. Relative to control groups, prizewinners switch research 
areas more frequently than expected ${ }^{28}$, while "inducement" prizes ${ }^{37}$ tend to attract more diverse ideas to a topic than normal. ${ }^{27,29}$ Building on the findings that prizes can affect an awardee's work, we investigate whether prizes signal the onset of topic-wide revolutionary changes in impact and talent. Our analysis uses new data on hundreds of recognized scientific prizes worldwide ${ }^{24}$ as well as on longitudinal data on the historical development of whole topics across the sciences. In this way, our work can contribute knowledge to tunderstanding the dynamics of unexpected changes in scientific thinking and talent ${ }^{6,38}$, and investment funding $5,39,40$.

The analytical challenege in investigating a link between prizes and scientific revolutions focuses on demonstrating that the expected growth trajectory of a topic significantly differs before and after the prize and that non-prizewinning topics that have levels of productivity, citations, and talent historically indistinguishable from those associated with the prizewinning topic do not experience extraordinary growth in the absence of a prize. We use difference-in-differences regression to test whether a prizewinning topic's growth trajectory after the prize is significantly greater than it was before the prize. To examine the dynamics of growth of comparable non-prizewinng topics, we used matching to identify five non-prizewinning topics with 10 years of talent and impact comparable to each prizewinning topic using proper adjustments that insure valid standard errors and parallel trend requirements are met ${ }^{17,41}$.

We collected data on scientific topics using Microsoft Academic Graph (MAG). MAG triangulates third party expert opinions and NLP algorithms to identify meaningful distinctions among "scientific fields of study" (a.k.a. "topics") ${ }^{42,43}$. The MAG analyzes the near universe of scientific works, covering over 172 million publications written by 209 million authors in 48,000 journals from 1800 to 2017. MAG classifies scientific knowledge hierarchically - disciplines $>$ domains $>$ and topics. Discipline, domain, and topic labels are based on the classifications published on Wikipedia and created through crowdsourcing. The discipline of psychology, for example, has domains that include neuroscience, social psychology, and developmental psychology, and each domain has 
many topics. MAG uses NLP to assign papers to topics. The algorithm that assigns a paper to a topic is based on a paper's complete text in relation to other texts, not just keywords.

We collected original data on 458 scientific prizes conferred 5,327 times between 1960 and 2017 and with respect to 11,539 scientific topics covering nearly all disciplines, celebrated awards like the Wolf Prize or Breakthrough Prize, and hundreds of lesser but recognized prizes from Wikipedia's "scientific prizes" pages ${ }^{24,35}$. To validate the crowdsourced Wikipedia data, we manually cross-checked it with data on prizes found on the web and print media. Prizes were linked to topics by associating the prizewinning scientist with their topics. A scientist was defined as having worked on a particular topic if they published at least 10 papers on that topic. The 10-paper threshold was validated using Wikipedia's "known for" dataset. The "known for" data lists the topics a scientist is associated with based on the crowdsourced opinions of other scientists. Consistent with our 10-paper threshold, a scientist published on average 10 papers on a topic if that topic is included in that scientist's known-for list on Wikipedia (see SI Appendix Sec. 1 for details on data collection and further robustness checks.)

Our test for the link between prizewinning and a topic's extraordinary growth in impact and talent used difference-in-differences regression with control variables ${ }^{17}$ (the Methods section presents model specification details). To establish a comparison set of non-prizewinning topics, we used a popular dynamic optimal matching method (DOM) ${ }^{44-}$ 47. DOM dynamically identifies a prizewinning and non-prizewinning group of peer topics from the same discipline that have statistically-indistinguishable annual growth and impact trends for 10 years before the prize year, automatically ensuring parallel trends between the prizewinning and non-prizewinning topics ${ }^{48,49}$. For each prizewinning topic, DOM identifies five peer topics that are matched on key measures of a topic's growth ${ }^{10-15}$ (hereafter the big five growth measures): its yearly number of (a) publications, (b) citations, (c) total citations by a topic's top 5\% most-cited scientists, (d) incumbent scientists, and (e) new entrants (rookie, experienced, and star scientists who publish for the first time on a topic). Figure 1 verifies the matching procedure. As required for our methodology, prizewinning and peer topics show no statistical differences for 10 years before the prize 
and the prizewinning year for all big five measures $(11$ years $* 5$ measures $=55$ tests, all pvalues $>0.23)$.

Figure 2 illustrates how we quantify revolutionary change using the big five measures. Revolutionary change is defined as occurring when the historic growth pattern on a big five measure deviates significantly from its expected growth trend as well as when it significantly deviates from the expected growth computed for peer topics:

$$
\Delta_{t}=\log \left(Y_{t}\right)-\log \left(\widetilde{Y}_{t}\right)
$$

$Y_{t}$ is the actual growth of one of the big five growth variables (e.g., publications; citations, etc.) measured yearly at time $t . \widetilde{Y}_{t}$ is the expected growth of the same variable based on the average growth of peer topics. Time $t$ 's range is -10 to +10 , with 0 corresponding to the prizewinning year. $\Delta_{t}=0.0$ indicates no difference in the growth of the prizewinning and peer groups. In analyzes, years before and after the prize year represent actual time in years (i.e., no rescaling) and the gold and black lines represent the prizewinning and peer groups, respectively. The SI reports confirmatory robustness checks for alternative measures of $\Delta_{t}$ (Fig. S5), the closeness of matched topics in terms of overlap of scientists or papers (Fig. S4), and matched case examples (Fig. S1 and Fig. S2).

\section{Results}

Prizewinning topics display extraordinary growth in productivity, impact, and talent that begins the year following the prize year and continues for at least the next 10 years. Our first test of the link between prizewinning and a topic's revolutionary growth applies our difference-in-differences analysis net of control variables. Table S10 shows that scientific topics, after being associated with a prize, grow unexpectedly large in terms of productivity, citation impact, the entry of star scientists, entry of rookie scientists, and the retention of scientists already working on the topic relative to peer topics $(p<0.001)$. 
Figures 3A-E plot the extraordinary magnitudes of revolutionary growth of our big five variables in prizewinning topics relative to peer topics using the DOM analysis. Several broad findings are noteworthy. First, the DOM method shown in the plots confirms the DID analysis. Second, The average magnitudes of $\Delta_{t}\left(e^{\Delta t}-1=\left(Y_{10}-\widetilde{Y_{10}}\right) / \widetilde{Y_{10}}\right)$ for our big five measures of growth indicate that at five years after the prize year, prizewinning topics have grown an average $16 \%$ to $30 \%$ larger than peer topics (all $\mathrm{p}-$ values $<0.0001)$. At five years after the prize year, work on prizewinning topics has grown an average $16 \%$ to $30 \%$ larger than peer topics. At 10 years after the prize, the growth gap increases to $22 \%$ to $53 \%$. Third, Figure $3 \mathrm{~F}$ shows that after the prize year, prizewinning topics also influence patents. Patents cite prizewinning topics papers significantly more than peer topic papers $(\mathrm{p}<0.0001)$.

Examining individual changes in more detail, we find that growth is sharpest for the "number of incumbent scientists" variable (Fig. 3D). After the year in which a topic becomes prizewinning, incumbent scientists continue to publish on that topic at a rate $53 \%$ $\left(\Delta_{10}=0.4279, e^{\Delta_{10}}-1=0.5340\right)$ higher than incumbent scientists publish on peer topics. Relatedly, prizewinning topics gain over 35\% more new entrants on average than peer topics do $\left(\Delta_{10}=0.3001, e^{\Delta_{10}}-1=0.35\right.$, Fig. 3E). About half of new entrants $(46.8 \%)$ are rookie scientists who appear to make their first publication and a long-term commitment to a prizewinning topic ${ }^{50}$.

Star scientists are among the influx of new entrants who begin working on the topic for the first time after it is associated with a prize. Star scientists are the 5\% most highlycited scholars at the level of their discipline (physics, chemistry, sociology, etc. $)^{51}$. Counting star scientists working on prizewinning topics before and after the prize, we found that prizewinning topics attract over $46 \%$ more star scientists on average than do peer topics $\left(\Delta_{10}=0.3811, e^{\Delta_{10}}-1=0.4639\right.$ ) (See SI Appendix Fig. S6 for details and related placebo test.)

Migrations of scientists to prizewinning topics correlate with increases in productivity, impact, and the topic's paradigmatic diversification. At 10 years, 
prizewinning topics are $38 \%$ more productive in terms of number of publications $\left(\Delta_{10}=\right.$ $0.3232, e^{\Delta_{10}}-1=0.3815$ ) than peer topics (Fig. $3 \mathrm{~A}$ ) and have $31 \%$ more yearly citations $\left(\Delta_{10}=0.2742, e^{\Delta_{10}}-1=0.3155\right)$. Figure $3 \mathrm{~B}$ shows that prizewinning topics experience a 7\% increase in citations per paper at year 10 than do papers in peer topics (Fig. S7), and the impact of top-cited scientists who work on the prizewinning topic is $22 \%$ greater than the impact of top-cited scientists working on non-prizewinning peer topics $\left(\Delta_{10}=0.2046, e^{\Delta_{10}}-1=0.2270\right.$, Fig 3C), which indicates that the increase in citations is topic-wide rather than a redistribution of citations ${ }^{36}$.

Prizewinning topics become paradigmatically diverse than matched peer topics. Paradigmatic diversification refers to the heterogeneity of concepts scientists use to study a topic ${ }^{1,52}$. To measure paradigmatic diversification, we created a master list of all the topics new entrants in prizewinning or peer topics had published on before becoming a new entrant. Topics in the master list were defined as different from one another if topics were associated with different disciplines ( $\mathrm{N}=19$ disciplines). The topic diversity of the master list was then measured using Shannon Entropy as: $S=-\sum_{j} p_{j} \log _{2} p_{j}$, where $j$ represents a discipline, and $p_{j}$ measures the probability that a topic in the list belongs to discipline $j$. We observe that paradigmatic diversity's distribution at $\Delta_{5} \geq 0$ and $\Delta_{10} \geq 0$ for prizewinning topics is significantly more diverse than peer topics (K-S test, for $\Delta_{10} \geq$ 0 group $p=5.78 \times 10^{-23}$, for $\Delta_{5} \geq 0$ group $p=2.76 \times 10^{-15}$ ).

Figure 4 shows that when $\Delta_{10}$ equals zero (i.e., no growth differences), prizewinning and peer topics have no significant difference in paradigmatic diversification. However, as $\Delta_{10}$ grows, diversification follows such that when $\Delta_{10}$ equals two, paradigmatic diversity is $17 \%$ greater for prizewinning topics than it is for peer topics ( $\beta=$ $\left.0.38, p=1.89 \times 10^{-245}\right)$.

Robustness checks corroborate the results. First, we examined whether fundings explains the results. Figure 5 indicates that levels of research funding do not explain the results. Available data show that funding levels are uncorrelated with the extraordinary growth of prizewinning topics. NIH funding before and after the prize's conferral are flat. 
Second, we ran "placebo" tests ${ }^{49,53,54}$ that pretend each peer topic is a prizewinning topic at year zero and found that peer topics continued to grow at expected rates (Fig. S8 in SI). Third, we tested whether the results were driven by a few overlie topics. To conduct this test, we examined the growth of each prizewinning topic and its specific five peers separately for all 11,539 prizewinning topics. We found more than $60 \%$ of the prizewinning topics have growth significantly larger than their specific matched peer group (binomial test, all $\mathrm{p}$ values $<0.001$ ), indicating that the results are not driven by outliers but represent the central tendency of the distribution (See SI, Tab.S9.)

Since preexisting growth trends do not account for the "prize effect," we examined whether a prize's signal strength explains the magnitude of a prizewinning topic's extraordinary growth. Two measures of a signal's strength are the cost of creating a signal and the signal's perceived status ${ }^{55,56}$. Signals that require resources to be created send stronger signals because they are hard to imitate ${ }^{57}$. Recency and prize money can measure a signal's costliness. Newer work on a topic indicates that a prizewinner chooses to devote effort and resources to that research topic rather than to other topics. Moneyed prizes indicate that valuable resources were dedicated to the work ${ }^{58}$. A prize's field-specificity is a measure of prestige. Field-specific prizes often have greater perceived within-field status than do general prizes. For instance, the Field's Medal in math is generally viewed as more prestigious than the general-science National Medal of Science Prize ${ }^{33,58}$.

Figure 6 plots the matrix of relationships between our three signal strength variables and our big five growth variables. Recency, money, and field-specificity are binary variables (high vs low strength) with recency split at the median of its distribution. The signal strength variables reliably predict $\Delta_{10}$ in 14 -out-of-15 cases. High strength values double or triple the predicted magnitude of growth. The last column in Figure 6 presents OLS standardized regression coefficients of the $\Delta_{10}$ of our five growth measures regressed on recency (entered as a continuous variable), money, and field-specificity. The estimates control for lagged values of each growth trend at times $t-1, t-2, t-3$ and $t-10$ years; discipline fixed effects; prizewinner is a star scientist or not; and the prize's conferral year, prize's 
age, and prize's total number of conferrals ${ }^{6,12,34}$ (See SI Appendix Regression Table S1-S8 for specific details.)

We find recency has the overall greatest signaling strength. A one standard deviation increase in recency is associated with a $14 \%$ increase in $\Delta_{10}$ of new scientists and a $14.7 \%$ increase in $\Delta_{10}$ of citations. Moneyed or field-specific prizes predict a $\Delta_{10}$ in publication of an average $4.7 \%$ or $7.2 \%$ over peer topics, respectively. These finding indicate that prizes reliably signal a topic's impending extraordinary growth in impact and scientific talent, and a prize's signaling strength strongly predicts the magnitude of exceptional growth. Robustness checks further confirm the findings generalize across time, prizes, and disciplines. ${ }^{59}$ (see Table S3-S7.)

\section{Discussion}

How scientists devote their research efforts affects their careers and collectively shapes scientific progress Funding agencies and universities similarly endeavor to invest in prosperous research areas and avoid spending on topics that will ultimately be proven fadish, yet knowledge of how scientists' collective actions impact science is nascent ${ }^{5,60,61}$.

We found that social signals strongly predict unexpectedly large changes in the migrations of scientists to specific research topics as well as a topic's increased growth and impact in a manner akin to Kuhn's scientific revolutions. The social signal we investigated is prizewinning ${ }^{24,34}$. Relative to the growth of peer topics that grew the same way as prizewinning topics did for 10 years before the prize's conferment, prizewinning topics have significantly more incumbents recommit their effort; rookie scientists make first time investments; and star scientists direct their efforts toward the prizewinning topic. Importantly, these demographic changes deepen and diversify the talent of the prizewinning topic, leading to more paradigmatic diversification and higher impact papers than peer topics. The magnitude of these changes was not found to be related to funding but to the signal strength of the prize. Prizes associated with the award-winning scientist's recent work, discipline-specific rather than general topics, and award money strongly 
predict the magnitude of growth that follows the prize. Counterfactual and placebo tests of peer topics that displayed statistically indistinguishable growth trends as prizewinning topics for 10 years before the prize showed only expected levels of growth.

Future research should further examine mechanisms that connect prizes and a topic's unexpected growth. Broadly, our findings are consistent with what Thomas Kuhn called the "essential tension between tradition and innovation" and with scientific revolutions ${ }^{1,4,62}$. Kuhn noted that conservative investment and risk-taking each play a role in scientific discovery. In line with Kuhn's essential tension, we found that prizewinning topics continue their existing tradition with a strengthened base of incumbents who reinvest in it and with new entrants who diversify paradigmatic viewpoints and experiences - the kinds of change in the demography of scientific teams and networks that are associated with novelty and impact ${ }^{39,63-67}$. Research on whether rookie scientists flock to prizewinning topics because it appears to be an especially promising professional opportunity, a topic of special intellectual attractiveness, or both could help understanding of generational changes in science. At the same time, understanding why targeted funding seems to matter little in getting scientists to migrate to and from topics - a finding consistent with other new work ${ }^{5}$ - could increase the understanding of how to actively shift scientists' research foci and improve institutions' strategic planning ${ }^{58,64,68}$.

The study has broad implications for science of science and science policy. This is among the first studies to reliability predict scientific revolutions and to conceptually link prizewinning to revolutions. For policy leaders, these findings demonstrate how scientists and institutions make risky research investment decisions, how investments link to tomorrow's innovative research topics, and how to predict the frontiers along which science evolves. Practicing scientist will find the information valuable in career planning and mentorship. Following our findings and methods, philosophers of science and researchers in the burgeoning field of science of science can begin a whole range of studies linking scientific revolutions and paradigm shifts to vast amounts of quantifiable data that has not been previously available or analyzed. Science policy implications are associated with funding. In an era when funding has been flat but the number of topics eligible for 
funding has continually increased, the efficacy of research spending is critical. The current funding system has limitations in several dimensions, including the weakness of grant scores for predicting funded research impact and researcher career success ${ }^{39}$. Additionally, even when targeted funding is prescient in backing the next important topic, that funding alone appears to do little to move researchers' investment effort away from their current projects and toward the targeted topic ${ }^{5}$. Our findings on prizewinning as a driver of collective shifts in effort suggest prizes provide a novel approach for predicting highpotential research that is complementary to other approaches by harnessing the collective intelligence of diverse scientific talent.

\section{Methods}

\section{Matching Design}

To study growth pattern before and after a topic is associated with a topic's prizewinning event, we find five topics in the same discipline that had growth patterns that were statistically indistinguishable from each other and the prizewinning topic for ten years before the prize year. We focus on topics where their first prizewinning event occurred in a 40-year period between 1970-2007, which includes 12,135 topics. Among the 12,135, 11,539 (more than $95 \%$ ) could be statistically matched to peer topics. If a topic is related to multiple prizewinners, we focus on the first prizewinner and the first prizewinning event to avoid possible bias in analysis.

Specifically, prizewinning and peer topics are matched on five longitudinal growth measures (hereafter referred to as the Big Five for brevity) on a yearly basis for a total of 11 years by 5 measures a year or 55 total matched observations:

(i) yearly number of new publications on a topic.

(ii) yearly number of new citations on a topic. 
(iii) average citations by the top 5\% most cited scientists in the topic where the top $5 \%$ most cited scientists based on their total number of citations over all topics they publish on.

(iv) number of incumbent scientists where incumbents are defined as scientists who previously published a paper on the topic before the certain year

(v) number of new entrants where entrants are defined as scientists who publish a paper on the topic for the first time in a certain year.

\section{Dynamic Optimal Matching (DOM) Method for Defining Peer Topics:}

To select the peer non-prizewinning topics, we use a Dynamic Optimal Matching method, which applies the Optimal Matching Method ${ }^{44,46,47}$ to a time series data, which simultaneously maximizes closeness and ensures fine balance characteristics that are essential to accurate matching $44,45,47,69$.

First we select a peer topic candidate pool ${ }^{46}$. To achieve this, for each prizewinning topic $i$, we selected up to 40 close-distance topics in terms of $\theta_{i, j}$ from the same discipline, generating a peer candidate pool. For $95 \%$ of the prizewinning topics, a proper peer candidate pool was identified $(11,539 / 12,135=95.08 \%)$. To achieve matching, we defined a distance measure $\theta_{i, j}$ to quantify the closeness between the prizewinning topic $i$ and a non-prizewinning topic $j^{17,70}$ :

$$
\theta_{i, j}=\frac{\sum_{n=1}^{N} \sum_{t=t^{*}-t_{0}}^{t^{*}}\left(\log Y_{i, n}(t)-\log Y_{j, n}(t)\right)^{2}}{N *\left(t_{0}+1\right)}
$$

, where $Y_{i, n}$ indicates the quantity for the topic $i$ in terms of one of the $N=5$ matched categories (i.e. yearly publications, yearly citations, \# of incumbent scientists, \# of new scientists, top scientist quality). $t$ measures number of years prior to the prizewinning year for topic $i$, where $t^{*}$ represents the prizewinning year for topic $i$, and $t_{0}=10$, indicates we traced the growth pattern for topics in a 11 -year duration, which includes 10 years prior to the prizewinning year. 
Second, to ensure the balance between the peer and prizewinning topics for the entire system and the closest topics are selected (i.e., "fine balance" and "closeness"), we further identify 5 peer topics for each prizewinning topic from the candidate pool. Specifically, we want to 1) minimize the distances between the peer and prizewinning topics in terms of $\theta_{i, j}$, and also 2) make sure the distribution of the peer and prizewinning topics are acceptably and simultaneously close for all 55 covariates. In other words, for each $t$ (time) and $n$ (the matching category), we should make sure the differences between the prizewinning groups and peer topics are small enough, where the difference between the prizewinning topic $i$ and its expected growth at time $t$ and category $n$ is quantified by $\Delta_{i, n}(t)=\left(\log Y_{i, n}(t)-\log \tilde{Y}_{i, n}(t)\right)$. The expected growth is obtained by averaging the trajectory of the matched topics. This problem is a classical optimization problem, which could be solved with typical Mixed Integer Programming (MIP) methods ${ }^{45,46}$. We found the best optimized matching possible where 1) the distance between the prizewinning topics and the peer topics is minimized; in the same time, 2) the difference between the peer and prizewinning groups is not statistically significant for any $t \in[-10,0]$ and $n \in$ $[1,5]$. Mathematically, we have:

$$
\left|\frac{\sum_{i=1}^{M} \Delta_{i, n}(t)}{M}-0\right|<1.96 * S E\left(\Delta_{i, n}(t)\right) . \text { for } \forall 1 \leq n \leq 5,-10 \leq t \leq 0
$$

Here $S E\left(\Delta_{i, n}(t)\right)$ measures the standard error of the $\Delta_{i, n}(t)$ for the prizewinning topics at time $t$ and in category $n$. To prevent bias by topics with a large $\Delta_{i, n}(t)$ in the MIP process, we also monitored the number of positive and negative $\Delta_{i, n}(t)$ for any $t \in[-10,0]$ and $n \in[1,5]$, to make sure that they are evenly distributed around zero. This method guarantees closeness between the peer and prizewinning topic and good balancing between the groups. 
Robustness Checks: Robustness check validated the DOM method.

A Placebo Test was performed as a second statistical validation (Fig. S8). In Fig.1, we have already shown that there is no difference between the peer and prizewinning topic before the prizewinning year, but whether the prizewinning topic's growth pattern could be explained by chance? To answer this question, we perform a placebo test for the DOM method ${ }^{49,53,54}$ tests. Specifically, for each of the prizewinning topic, we selected one of its peer topics as a "pretend winning topic". We repeated the same DOM process for each pretend topic, obtaining five new peer topics for each pretend topic. By comparing the growth pattern of the pretend topic and its peers, we can test whether growth patterns are alike for topics without a prizewinning event. In Fig. S8, we show that there is no difference in the expected growth for pretend topic before and after the prizewinning.

A Difference in Difference regression analysis was also used in our study. The outcomes can be expressed as following:

$$
Z_{i, t}=\beta_{0}+\beta_{1} \text { Treat }_{i}+\beta_{2} \text { Period }_{t}+\beta_{3} \text { Treat }_{i} * \text { Period }_{t}+D_{i}+\epsilon_{i, t, d},
$$

where $Z_{i, t}$ is the outcome variable, quantifying the impacts of topic $i$ at time $t$ using each of the big five growth variables defined in the main text. Treat $_{i}$ is a dummy variable quantifying whether the topic $i$ is a prizewinning topic or a non-prizewinning topic from a matched peer group as defined in the text. Period $_{t}$ is a dummy variable measuring whether time $t$ is before or after the prizewinning event ${ }^{41}$. If the topic belongs to the peer group, the prizewinning year of the related prizewinning topic will be used as the reference point. Control variables including fixed effects for discipline and specific prizewinning year are captured by term $D_{i} . \epsilon_{i, t, d}$ is an error term.

In Tab. S10, we show the regression results of the analysis. We find $\beta_{1}$ (coefficient for the Treat $\left._{i}\right)$ is not significant ( $P$ value $>0.05$ ) for all five categories, indicating that there is no difference between the prizewinning topics and the peer topics before the 
prizewinning event, further corroborating the accuracy of the DOM method. By contrast, we find both $\beta_{2}$ and $\beta_{3}$ are significantly larger than 0 for all five categories ( $P$ value $<$ 0.001), demonstrating that topics associated with a prize grow at unexpected rates after the prize relative to the matched peer group topics. $\beta_{3}$ also provides an estimation of the average value of $\Delta_{t}$ for each category.

\section{Acknowledgments}

We thank Jonas Lindholm-Uzzi, Meghan Stagl, and Yiting Wen for their help in data collection. Funding: This material is based upon work supported wholly or in part by the Northwestern Institution on Complex Systems (NICO) and the Air Force Office of Scientific Research under award number FA9550-19-1-0354.

Author Contributions: CJ, YM, and BU collected data, designed the study, and wrote the paper. CJ and BU conducted analyses. Competing Interests: The authors declare no competing interests in this work. Data Availability: Data used in this work are publicly available from Wikipedia and Microsoft Academic Graph. For further inquiry, please contact the corresponding author. Code Availability: The code used in this study is available from the corresponding author upon reasonable request. 


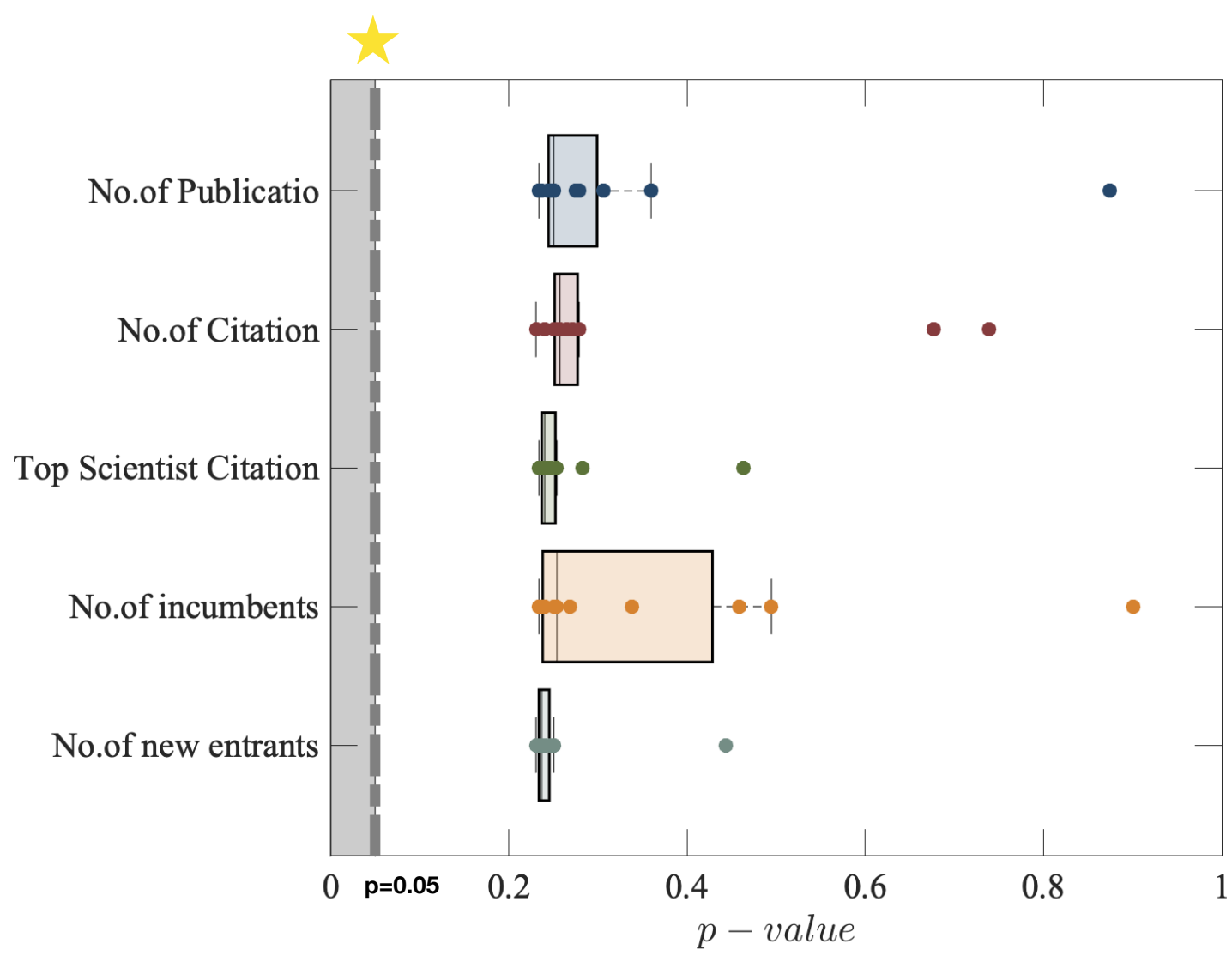

Figure 1. Prizewinning and Matched Non-prizewinning Peer Topics Have Statistically Indistinguishable Historical Growth Patterns Prior to the Prize Year. Based on five measures of a topic's growth (number of publications, number of citations, total citation of top scientists, number of incumbent scientists, and number of new entrant scientists), we observed that for 11 consecutive years before the year the prizewinning topic is awarded its prize, the prizewinning topic and its peer topic have statistically indistinguishable growth patterns. Box plots show median and $90^{\text {th }}$ and $10^{\text {th }}$ percentiles of the $p$-value of the 11 statistical tests, one for each year prior to the prize year. All tests of all measures $(11 * 5==55$ measures, dots) have a $p$ value $>0.05$ (dashed line). 


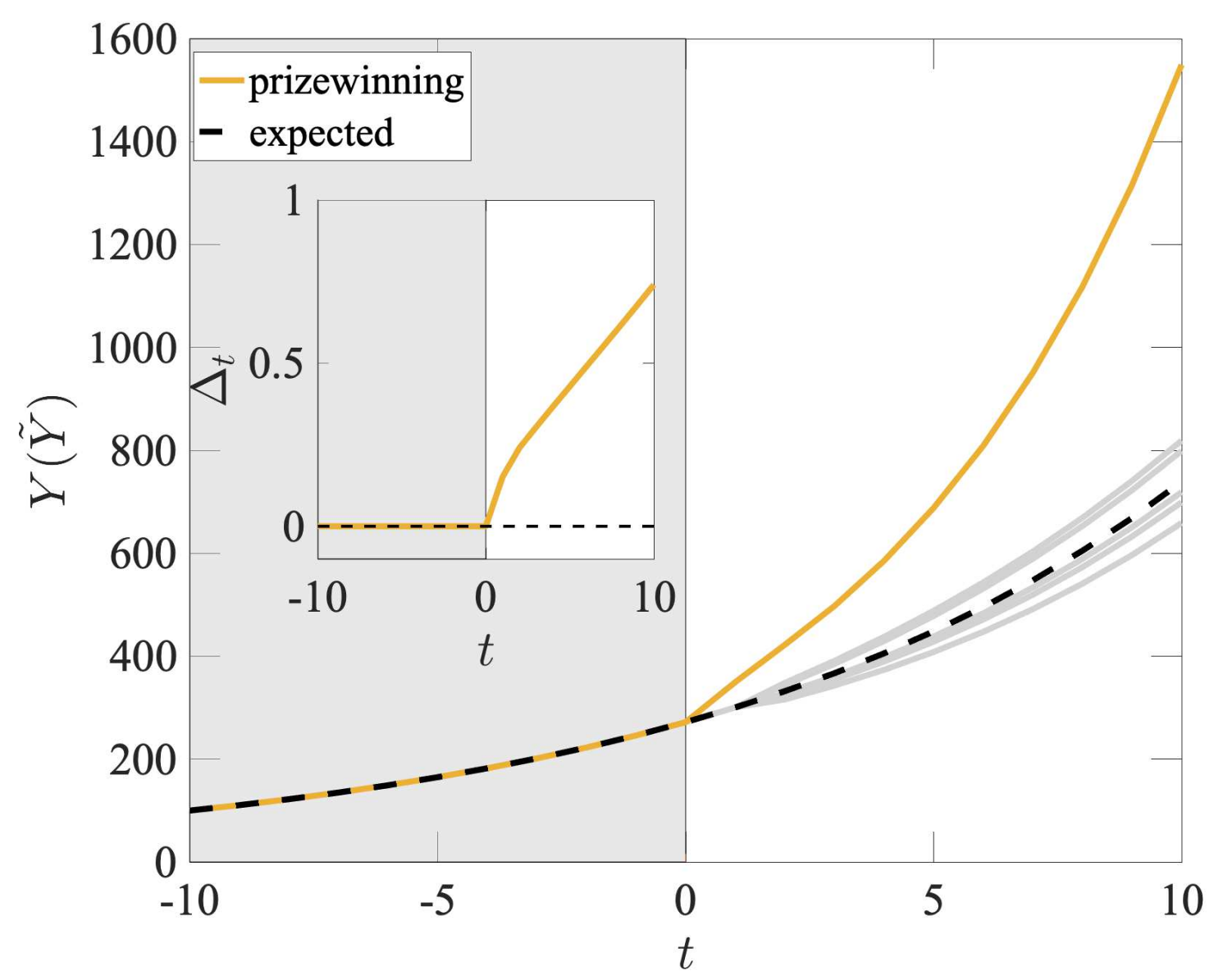

Figure 2. Quantifying Scientific Revolutions. Using the Dynamical Optimal Matching Method (DOM), we found five peer topics that have had similar growth trajectories as the prizewinning topic and each other according to five growth measures (annual citations, productivity, new entrants, incumbents, and star scientists) for 11 years $(11 * 5=55$ data points, gray panel) prior to the prizewinning year $(t=0) . \Delta_{t}$ is the difference between the log of the average growth of prizewinning topics minus the log of the average growth of peer topics. The inset shows $\Delta_{t}$ as relative percentage growth of the prizewinning and peer topic groups. 

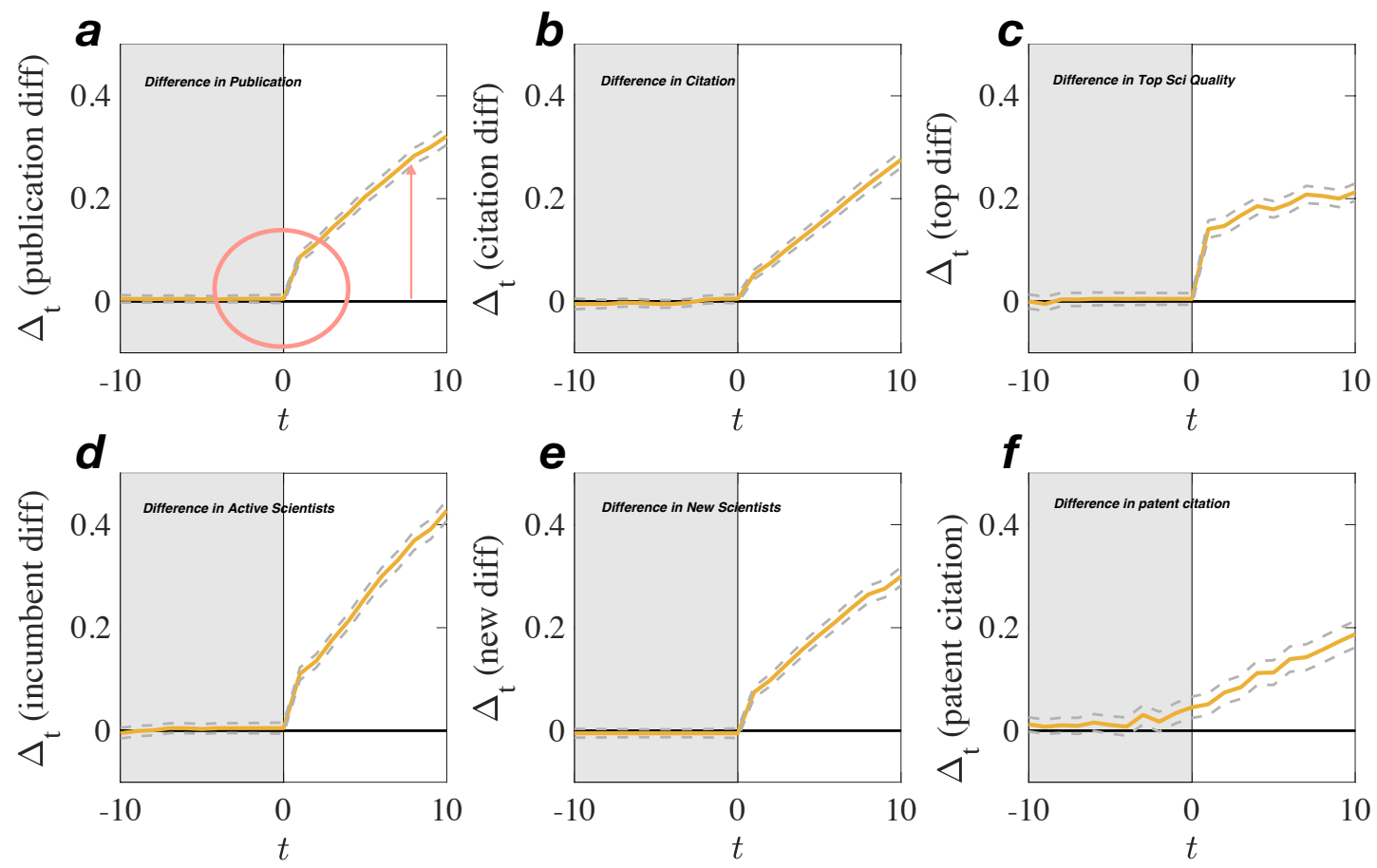

Figure 3. Scientific Prizes Signal Revolutionary Growth of Scientific Topics and Inventions. Panels (a) through (e) show the differences in growth rates of prizewinning and peer topics for 10 years prior to and 10 years after the prize year in relation to (a) \#publications, (b) \#citations, (c) \#citations by a topic's top scientists, (d) \#incumbent scientists, and (e) \#new scientists to the topic. Prizewinning and non-prizewinning peer topic groups are matched longitudinally using the DOM Method. The gold line represents the difference between prizewinning and peer group growth rates with 95\% CIs (See Eq. 1.) and the red circle represents the year of the prize.

Prizewinning and peer topic groups have no statistical difference for all 10 years before the prize $(\mathrm{p}>0.1$ for $5 \times 11=55$ covariate data points). Statistically significant growth differentials (gold minus black line) begin shortly after the prize (red circle) and compound yearly following the prize (red arrow). At 10 years, the growth rates of prizewinning topics exceed peer topics by $22 \%$ to $53 \%$ depending on the growth variable (\#publications, \#citations , \#active incumbent scientists, \#new entrants, \#citations by top scientists on topic ). Panel (f) shows the association between prizewinning and yearly growth in citations from patents. (SI appendix Fig. S7 reports robustness checks.) 


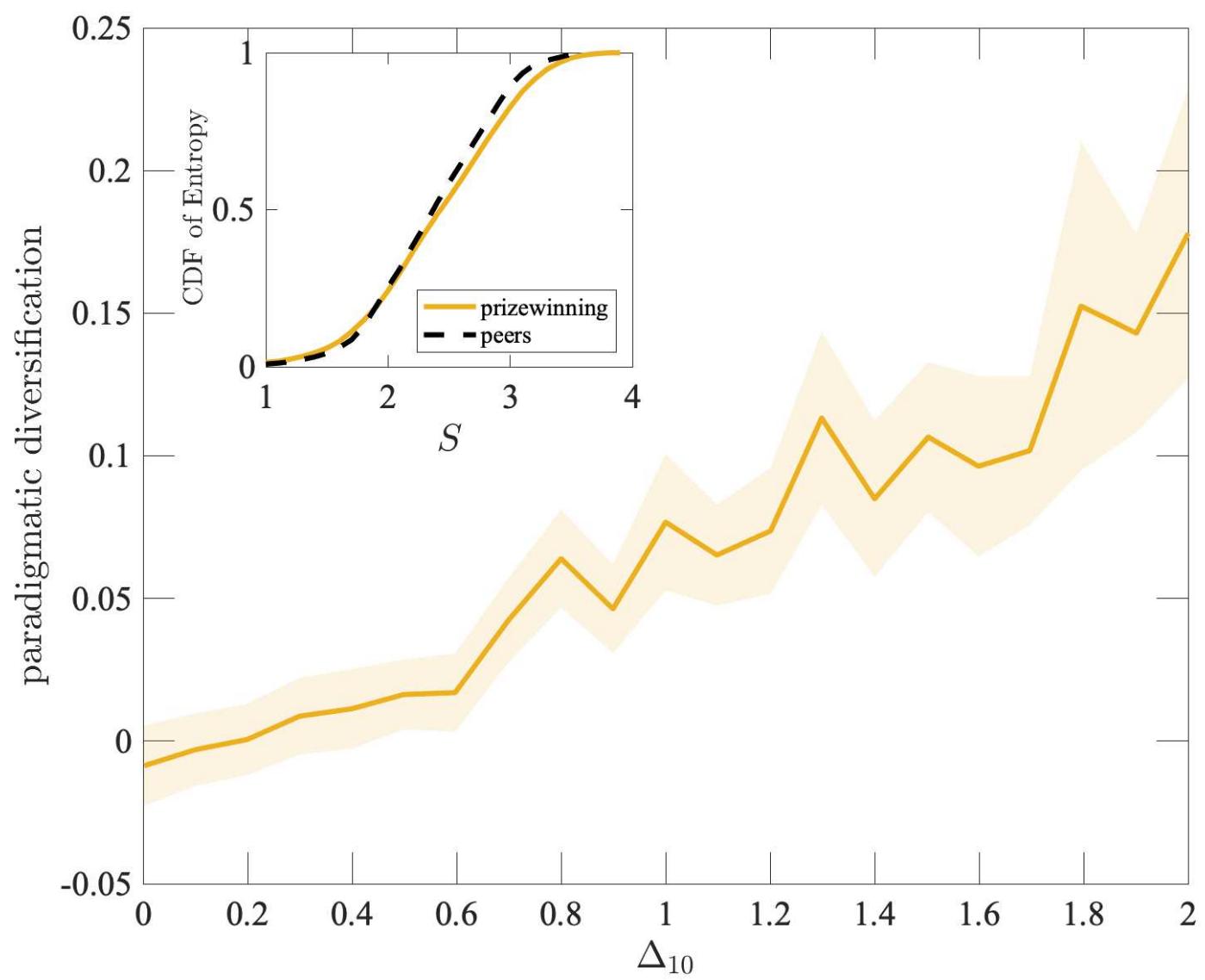

Figure 4: Prizes and Paradigmatic Diversification. The plot shows the percentage increase in paradigmatic diversification for prizewinning topics relative to peer topics (measure explained in the text). The inset shows the cummulative distribution of the paradigmatic diversity of the prizewinning topics with and their peer groups signifcantly differ (K-S test, $p=5.78 * 10^{-23}$ ). The relationship between revolutionary growth and paradigmatic diversity shows that as increases, relative paradigmatic diversity increases significantly $\left(\beta=0.38, p=1.89 \times 10^{-245}\right)$. At $\Delta_{t}$ equal to two, a prizewinning topic is estimated to be $17 \%$ more diverse paradigmatically than its peer topics. 


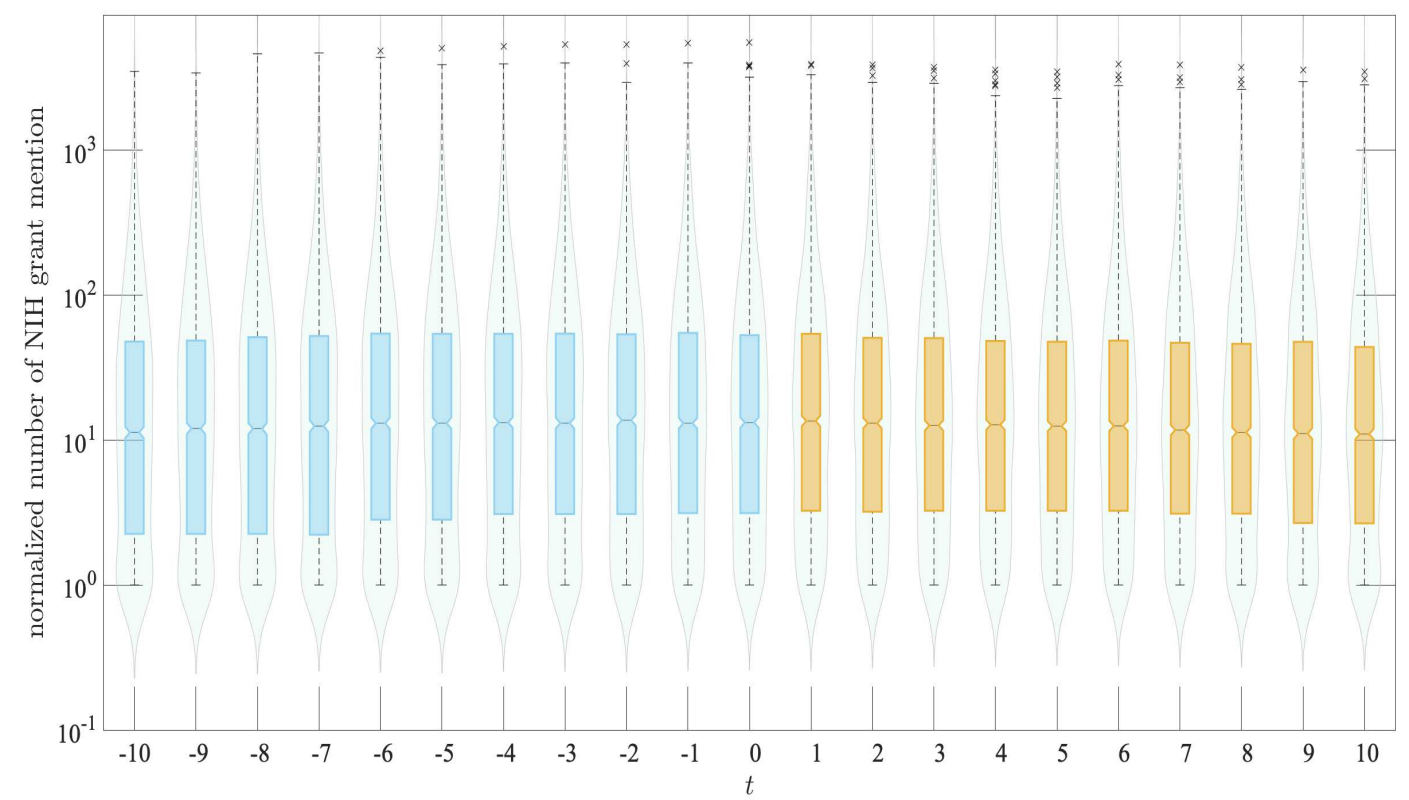

Figure 5. Funding and Revolutionary Growth are Unrelated. Normalized NIH grant funding is flat before and after the prizewinning event, demonstrating that funding levels are unrelated to the extraordinary growth of prizewinning topics. Analysis includes 2,921 prizewinning topics that received at least one NIH funding mention from 1985 to 2005; funding levels are normalized over time by dividing the number of grant mentions by the total number of grants in that year (see SI). The center line of the box plot is the median of the normalized grants, box limits correspond to the data's first and third quartiles, notches represent $95 \% \mathrm{CI}$, and violin plots represent the data's distribution. 


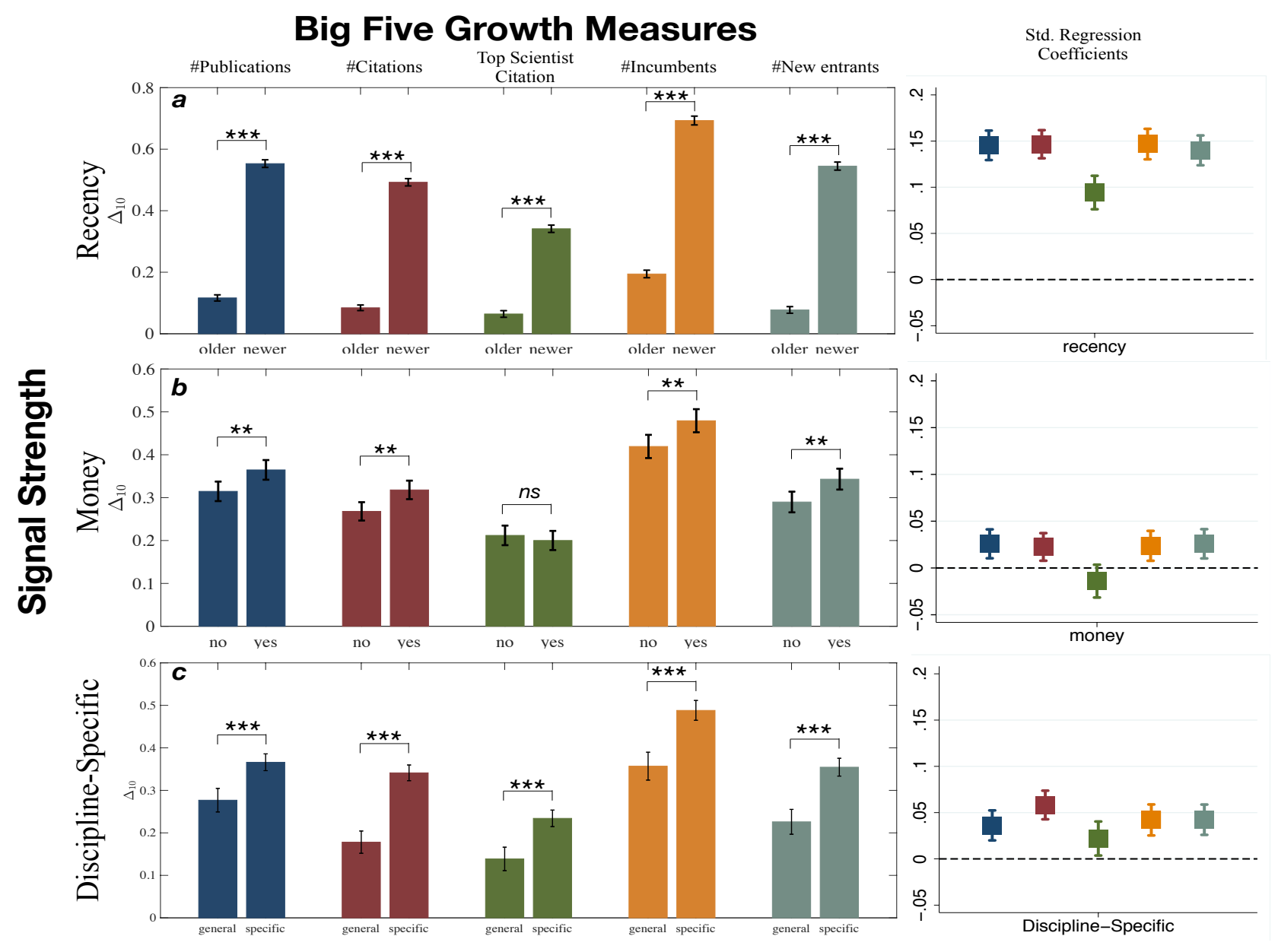

Figure 6. Signal Strength and Revolutionary Growth. Plots (a) through (c) show the ability of a prize's signal strength (measured as recency, money, or specialty) to predict a prizewinning topic's magnitude of unexpected growth $\left(\Delta_{t}\right)$ on five growth measures (number of publications, citations, citations by the topic's most-cited scientists, incumbents, and newcomers). Bar plots (with $95 \%$ CIs) report the average $\Delta_{t}$ by signal strength predictor. The coefficient plots adjacent to the bar plots show the standardized coefficients from a regression of $\Delta_{t}$ on all signal strength variables; lagged outcome variables at $t=-1,-2,-3,-10$; and fixed effects for discipline, prize year, prize age, and number of prize conferrals. The standardized coefficients indicate the relative predictive power of each signal strength variable and the generalizability and robustness of predictions across disciplines and in the presence of potential confounding variables $(* * * \mathrm{p}$ $<0.001$; ** $\mathrm{p}<0.01$; and $* \mathrm{p}<0.05$ ). 


\section{References}

1 Kuhn, T. S. The Structure of Scientific Revolutions. (University of Chicago, 1970).

2 Börner, K., Rouse, W. B., Trunfio, P. \& Stanley, H. E. Forecasting innovations in science, technology, and education. Proceedings of the National Academy of Sciences 115, 12573-12581 (2018).

3 Clauset, A., Larremore, D. B. \& Sinatra, R. Data-driven predictions in the science of science. Science 355, 477-480 (2017).

4 Foster, J. G., Rzhetsky, A. \& Evans, J. A. Tradition and innovation in scientists' research strategies. American Sociological Review 80, 875-908 (2015).

$5 \quad$ Myers, K. The elasticity of science. American Economic Journal: Applied Economics (2020).

6 Fortunato, S. et al. Science of science. Science 359, doi:10.1126/science.aao0185 (2018).

$7 \quad$ Penner, O., Pan, R. K., Petersen, A. M., Kaski, K. \& Fortunato, S. On the predictability of future impact in science. Scientific reports 3, 3052 (2013).

8 Petersen, A. et al. Reputation and impact in academic careers. PNAS 111, 1531615321 (2014).

9 Kleinberg, J. \& Oren, S. in Proceedings of the forty-third annual ACM symposium on Theory of computing. 529-538.

10 Upham, S. P. \& Small, H. Emerging research fronts in science and technology: patterns of new knowledge development. Scientometrics 83, 15-38, doi:10.1007/s11192-009-0051-9 (2010).

11 Griffiths, T. L. \& Steyvers, M. Finding scientific topics. Proceedings of the National academy of Sciences 101, 5228-5235 (2004).

12 Ataman, L. M., Ma, Y., Duncan, F. E., Uzzi, B. \& Woodruff, T. K. Quantifying the growth of oncofertility. Biology of reproduction 99, 263-265 (2018).

13 Bettencourt, L., Kaiser, D., Kaur, J., Castillo-Chavez, C. \& Wojick, D. Population modeling of the emergence and development of scientific fields. Scientometrics 75, 495-518 (2008).

14 Mane, K. K. \& Börner, K. Mapping topics and topic bursts in PNAS. Proceedings of the National Academy of Sciences 101, 5287-5290 (2004).

15 Small, H. Tracking and predicting growth areas in science. Scientometrics 68, 595-610, doi:10.1007/s11192-006-0132-y (2006).

16 Angrist, J., Azoulay, P., Ellison, G., Hill, R. \& Lu, S. F. Economic research evolves: Fields and styles. American Economic Review 107, 293-297 (2017).

17 Jin, G. Z., Jones, B., Lu, S. F. \& Uzzi, B. The reverse Matthew effect: Consequences of retraction in scientific teams. Review of Economics and Statistics 101, 492-506 (2019).

18 Bol, T., de Vaan, M. \& van de Rijt, A. The Matthew effect in science funding. Proceedings of the National Academy of Sciences 115, 4887-4890 (2018).

19 Merton, R. K. The Matthew effect in science: The reward and communication systems of science are considered. Science 159, 56-63 (1968). 
20 Callaham, M., Wears, R. L. \& Weber, E. Journal prestige, publication bias, and other characteristics associated with citation of published studies in peer-reviewed journals. Jama 287, 2847-2850 (2002).

21 Way, S. F., Morgan, A. C., Larremore, D. B. \& Clauset, A. Productivity, prominence, and the effects of academic environment. Proceedings of the National Academy of Sciences, 201817431, doi:10.1073/pnas.1817431116 (2019).

22 Merton, R. K. The Matthew effect in science, II: Cumulative advantage and the symbolism of intellectual property. Isis 79, 606-623 (1988).

23 Zuckerman, H. Scientific Elite: Nobel Laureates in the United States. (Free Press, 1977).

24 Ma, Y. \& Uzzi, B. Scientific prize network predicts who pushes the boundaries of science. Proceedings of the National Academy of Sciences 115, 12608-12615 (2018).

25 Crawford, E. T. The beginnings of the Nobel institution: the science prizes, 19011915. (Cambridge University Press, 1987).

26 Stiglitz, J. Give prizes not patents. New Scientist 16 (2006).

27 Moser, P. \& Nicholas, T. Prizes, Publicity and Patents: Non - Monetary Awards as a Mechanism to Encourage Innovation. The Journal of Industrial Economics 61, 763-788 (2013).

28 Azoulay, P., Graff Zivin, J. S. \& Manso, G. Incentives and creativity: evidence from the academic life sciences. The RAND Journal of Economics 42, 527-554 (2011).

29 Brunt, L., Lerner, J. \& Nicholas, T. Inducement prizes and innovation. The Journal of Industrial Economics 60, 657-696 (2012).

30 Lincoln, A. E., Pincus, S., Koster, J. B. \& Leboy, P. S. The Matilda Effect in science: Awards and prizes in the US, 1990s and 2000s. Social studies of science 42, 307-320 (2012).

31 Borjas, G. J. \& Doran, K. B. Prizes and productivity how winning the fields medal affects scientific output. Journal of human resources 50, 728-758 (2015).

32 Chari, V. V., Golosov, M. \& Tsyvinski, A. Prizes and patents: Using market signals to provide incentives for innovations. Journal of Economic Theory 147, 781-801 (2012).

33 English, J. F. The economy of prestige: Prizes, awards, and the circulation of cultural value. (Harvard University Press, 2008).

34 Zuckerman, H. The proliferation of prizes: Nobel complements and Nobel surrogates in the reward system of science. Theoretical Medicine 13, 217-231 (1992).

35 Ma, Y., Mukherjee, S. \& Uzzi, B. Mentorship and protégé success in STEM fields. Proceedings of the National Academy of Sciences (2020).

36 Reschke, B. P., Azoulay, P. \& Stuart, T. E. Status spillovers: The effect of statusconferring prizes on the allocation of attention. Administrative Science Quarterly, 0001839217731997 (2017).

37 Williams, H. Innovation inducement prizes: Connecting research to policy. Journal of Policy Analysis and Management 31, $752-776$ (2012). 
38 Merton, R. K. The Sociology of Science. (University of Chicago Press, 1973).

39 Wang, Y., Jones, B. F. \& Wang, D. Early-career setback and future career impact. Nature communications 10, 4331, doi:10.1038/s41467-019-12189-3 (2019).

40 Graves, N., Barnett, A. G. \& Clarke, P. Funding grant proposals for scientific research: retrospective analysis of scores by members of grant review panel. Bmj 343, d4797 (2011).

41 Bertrand, M., Duflo, E. \& Mullainathan, S. How much should we trust differences-in-differences estimates? The Quarterly journal of economics 119, 249-275 (2004).

42 Sinha, A. et al. in Proceedings of the 24th international conference on world wide web. 243-246 (ACM).

43 Wang, K. et al. A Review of Microsoft Academic Services for Science of Science Studies. Frontiers in Big Data 2, 45 (2019).

44 Rosenbaum, P. R. Optimal matching for observational studies. Journal of the American Statistical Association 84, 1024-1032 (1989).

45 Zubizarreta, J. R. Using mixed integer programming for matching in an observational study of kidney failure after surgery. Journal of the American Statistical Association 107, 1360-1371 (2012).

46 Pimentel, S. D., Kelz, R. R., Silber, J. H. \& Rosenbaum, P. R. Large, sparse optimal matching with refined covariate balance in an observational study of the health outcomes produced by new surgeons. Journal of the American Statistical Association 110, 515-527 (2015).

47 Rosenbaum, P. R. Modern Algorithms for Matching in Observational Studies. Annual Review of Statistics and Its Application 7 (2019).

48 Abadie, A. Semiparametric difference-in-differences estimators. The Review of Economic Studies 72, 1-19 (2005).

49 Abadie, A., Diamond, A. \& Hainmueller, J. Synthetic control methods for comparative case studies: Estimating the effect of California's tobacco control program. Journal of the American statistical Association 105, 493-505 (2010).

50 Millar, M. M. Interdisciplinary research and the early career: The effect of interdisciplinary dissertation research on career placement and publication productivity of doctoral graduates in the sciences. Research Policy 42, 1152-1164 (2013).

51 Azoulay, P., Zivin, J. S. \& Wang, J. Superstar Extinction. Quarterly Journal of Economics 125, 549-589 (2010).

52 Jones, B. F. The burden of knowledge and the 'Death of the Renaissance Man': Is innovation getting harder? Review of Economic Studies (2008).

53 Abadie, A., Diamond, A. \& Hainmueller, J. Comparative politics and the synthetic control method. American Journal of Political Science 59, 495-510 (2015).

54 Kreif, N. et al. Examination of the synthetic control method for evaluating health policies with multiple treated units. Health economics 25, 1514-1528 (2016).

55 Spence, M. Signaling in retrospect and the informational structure of markets. American Economic Review 92, 434-459 (2002). 
56 Pentland, A. Honest signals: how they shape our world. (MIT press, 2010).

57 Podolny, J. M. Status signals: A sociological study of market competition. (Princeton University Press, 2010).

58 Ma, Y., Oliveira, D. F. M., Woodruff, T. K. \& Uzzi, B. (Nature Publishing Group, 2019).

59 Raftery, A. E. Bayesian model selection in social research. Sociological methodology, 111-163 (1995).

60 Morgan, N. \& Thompson, J. A worthwhile investment: research-council scientists speak out. Philosophical Transactions of the Royal Society of London. Series A: Mathematical, Physical and Engineering Sciences 360, 2671-2680 (2002).

61 Granovetter, M. Society and economy. (Harvard University Press, 2017).

62 Kuhn, T. S. The essential tension: Tradition and innovation in scientific research. Scientific creativity: Its recognition and development. New York: Wiley, 341-354 (1963).

63 Wuchty, S., Jones, B. F. \& Uzzi, B. The increasing dominance of teams in production of knowledge. Science 316, 1036-1039 (2007).

64 Jones, B. F., Wuchty, S. \& Uzzi, B. Multi-University Research Teams: Shifting Impact, Geography, and Stratification in Science. Science 322, 1259-1262, doi:DOI 10.1126/science.1158357 (2008).

65 Uzzi, B., Mukherjee, S., Stringer, M. \& Jones, B. Atypical combinations and scientific impact. Science 342, 468-472 (2013).

66 Mukherjee, S., Romero, D. M., Jones, B. \& Uzzi, B. The nearly universal link between the age of past knowledge and tomorrows breakthroughs in science and technology: The hotspot. Sci Adv 3, 2017, doi:e1601315 (2017).

67 Guimerà, R., Uzzi, B., Spiro, J. \& Amaral, L. A. N. Team Assembly Mechanisms Determine Collaboration Network Structure and Team Performance. Science 308, 697-702 (2005).

68 Woodruff, T. K., Oliveira, D. F. \& Ma, Y. Sex Differences in Grant FundingReply. Jama 322, 579-580 (2019).

69 Stuart, E. A. Matching methods for causal inference: A review and a look forward. Statistical science: a review journal of the Institute of Mathematical Statistics 25, 1 (2010).

70 Lu, S. F., Zhe Jin, G., Uzzi, B. \& Jones, B. The Retraction Penalty: Evidence from the Web of Science. Nature Scientific Reports 3 (2013). 


\section{Figures}

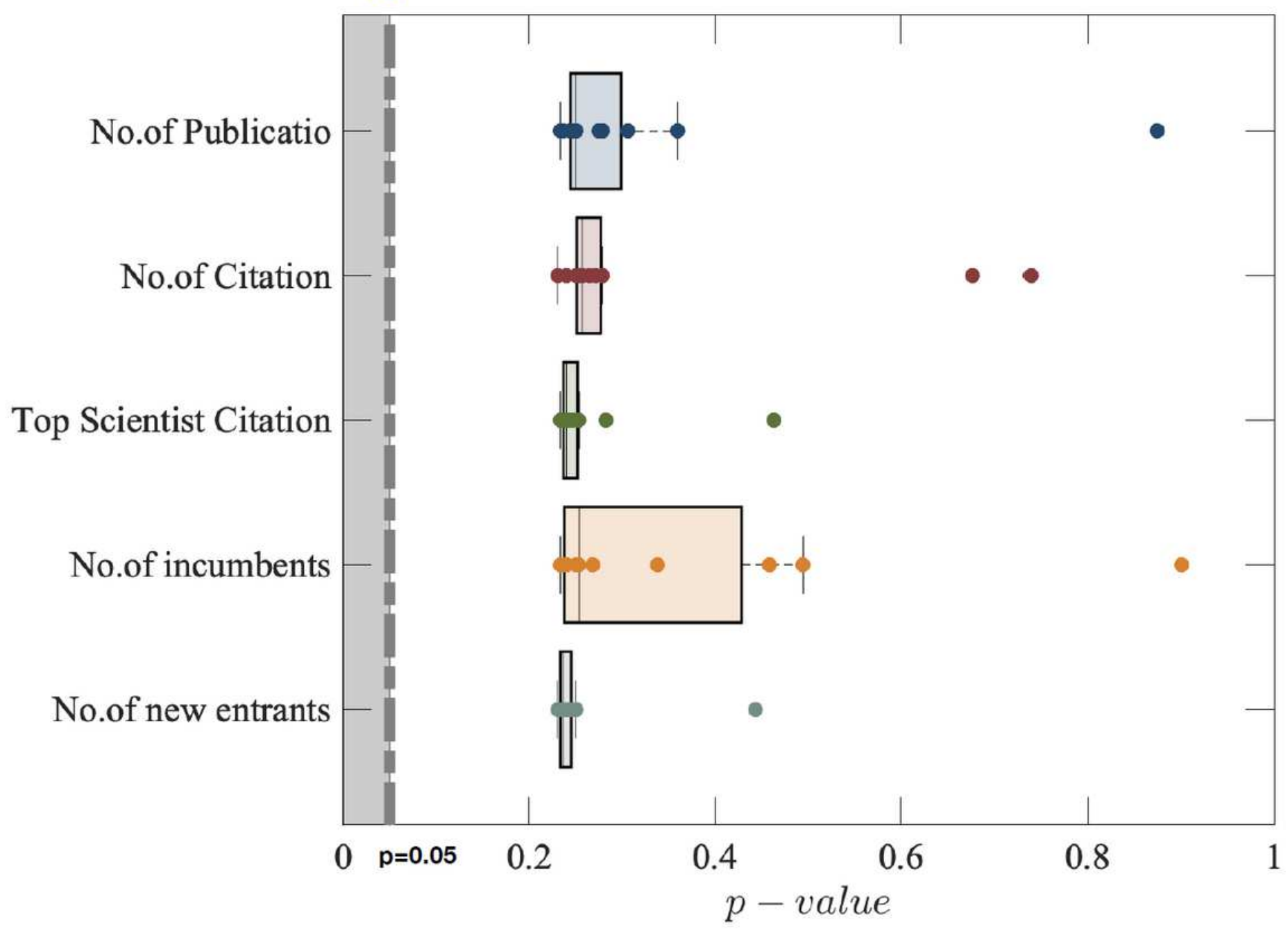

Figure 1

Prizewinning and Matched Non-prizewinning Peer Topics Have Statistically Indistinguishable Historical Growth Patterns Prior to the Prize Year. Based on five measures of a topic's growth (number of publications, number of citations, total citation of top scientists, number of incumbent scientists, and number of new entrant scientists), we observed that for 11 consecutive years before the year the prizewinning topic is awarded its prize, the prizewinning topic and its peer topic have statistically indistinguishable growth patterns. Box plots show median and 90th and 10th percentiles of the $p$-value of the 11 statistical tests, one for each year prior to the prize year. All tests of all measures $(11 * 5==55$ measures, dots) have a pvalue $>0.05$ (dashed line). 


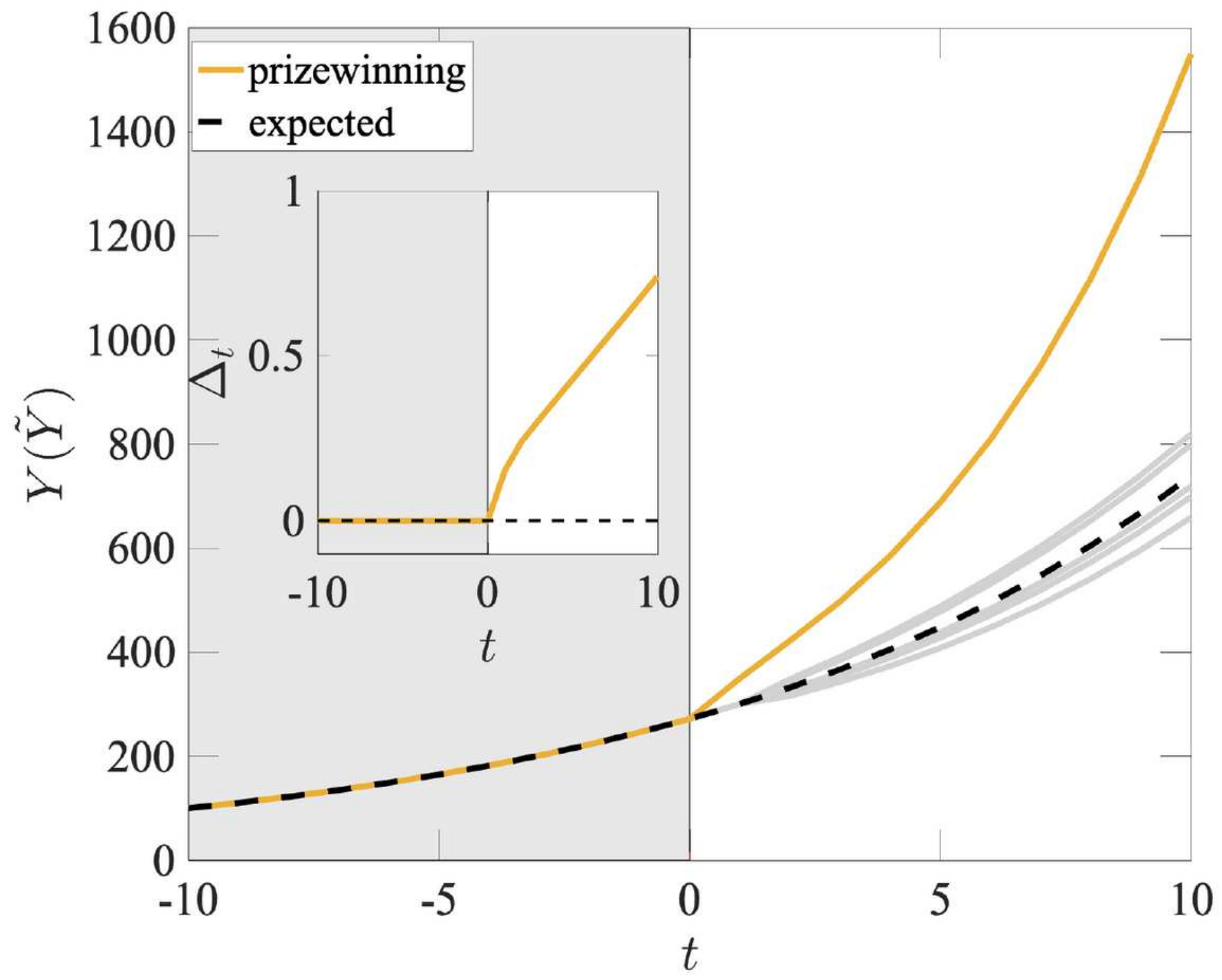

Figure 2

Quantifying Scientific Revolutions. Using the Dynamical Optimal Matching Method (DOM), we found five peer topics that have had similar growth trajectories as the prizewinning topic and each other according to five growth measures (annual citations, productivity, new entrants, incumbents, and star scientists) for 11 years $(11 * 5=55$ data points, gray panel) prior to the prizewinning year $(t=0) . \Delta t$ is the difference between the log of the average growth of prizewinning topics minus the log of the average growth of peer topics. The inset shows $\Delta t$ as relative percentage growth of the prizewinning and peer topic groups. 

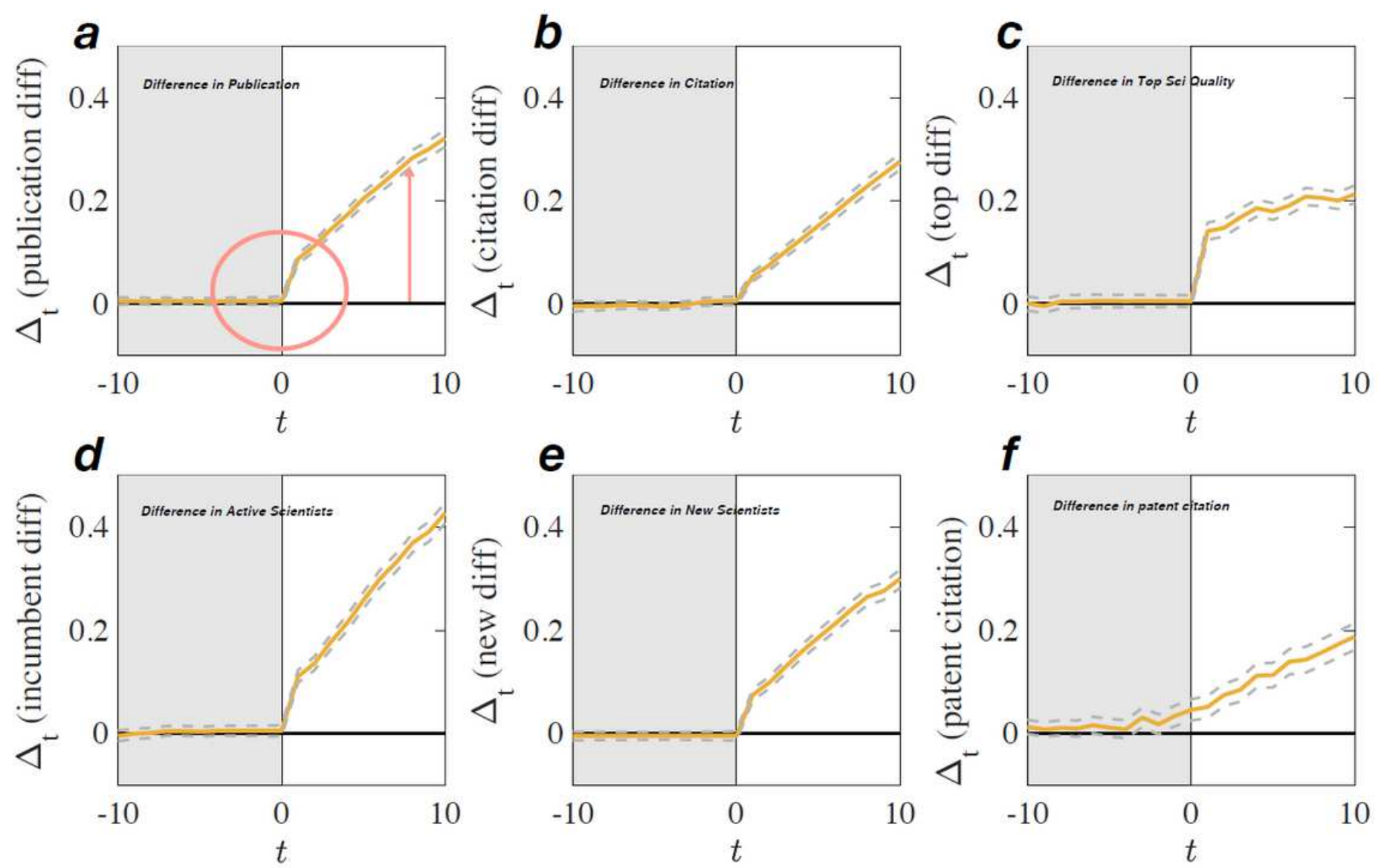

\section{Figure 3}

Scientific Prizes Signal Revolutionary Growth of Scientific Topics and Inventions. Panels (a) through (e) show the differences in growth rates of prizewinning and peer topics for 10 years prior to and 10 years after the prize year in relation to (a) \#publications, (b) \#citations, (c) \#citations by a topic's top scientists, (d) \#incumbent scientists, and (e) \#new scientists to the topic. Prizewinning and non-prizewinning peer topic groups are matched longitudinally using the DOM Method. The gold line represents the difference between prizewinning and peer group growth rates with $95 \% \mathrm{Cls}$ (See Eq. 1.) and the red circle represents the year of the prize. Prizewinning and peer topic groups have no statistical difference for all 10 years before the prize ( $p>0.1$ for $5 \times 11=55$ covariate data points). Statistically significant growth differentials (gold minus black line) begin shortly after the prize (red circle) and compound yearly following the prize (red arrow). At 10 years, the growth rates of prizewinning topics exceed peer topics by $22 \%$ to $53 \%$ depending on the growth variable (\#publications, \#citations, \#active incumbent scientists, \#new entrants, \#citations by top scientists on topic). Panel ( $f$ ) shows the association between prizewinning and yearly growth in citations from patents. (SI appendix Fig. S7 reports robustness checks.) 


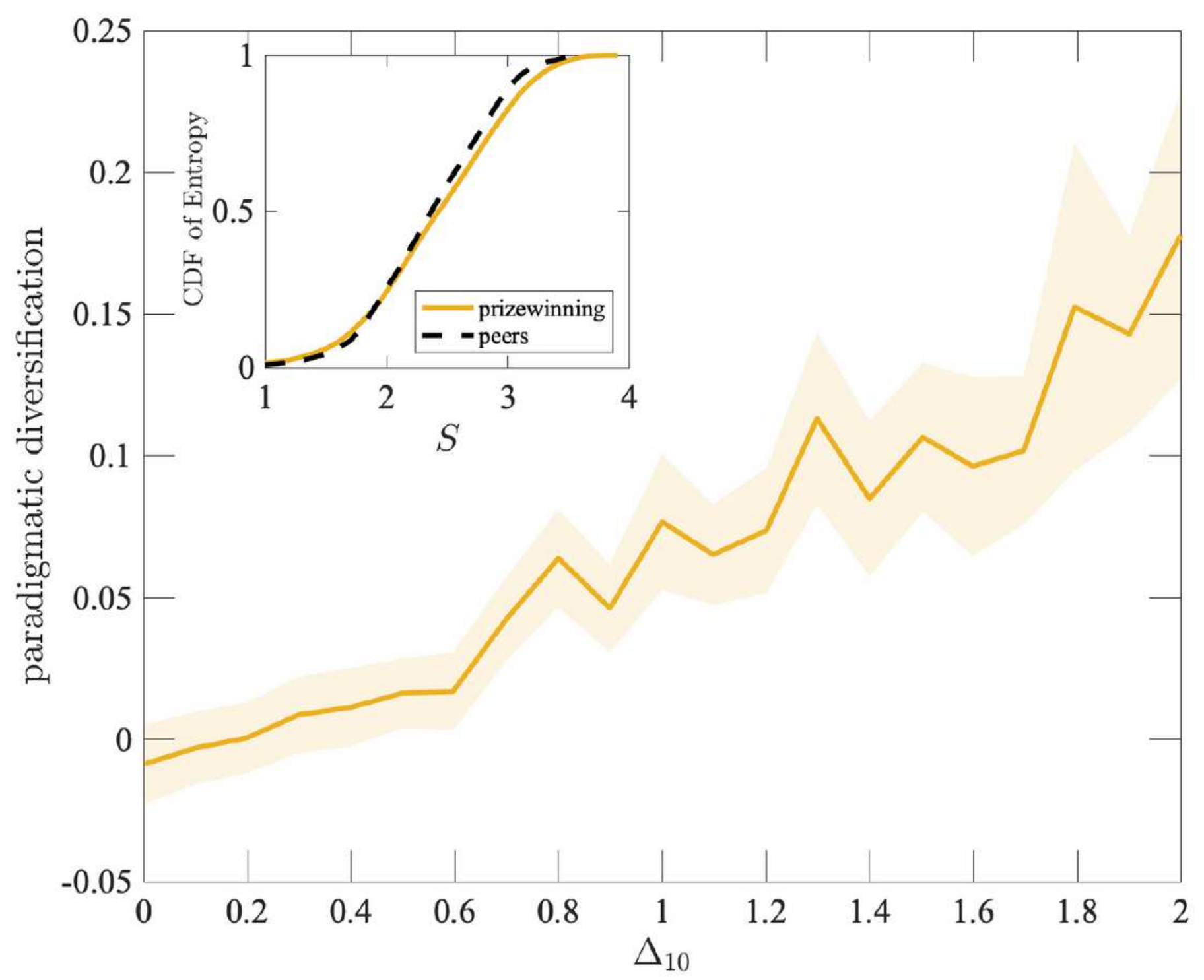

Figure 4

Prizes and Paradigmatic Diversification. The plot shows the percentage increase in paradigmatic diversification for prizewinning topics relative to peer topics (measure explained in the text). The inset shows the cummulative distribution of the paradigmatic diversity of the prizewinning topics with and their peer groups signifcantly differ (K-S test, $\otimes=5.78 \otimes 10-23$ ). The relationship between revolutionary growth and paradigmatic diversity shows that as increases, relative paradigmatic diversity increases significantly $(\mathbb{Q}=0.38, \nabla=1.89 \times 10-245)$. At $\Delta$ t equal to two, a prizewinning topic is estimated to be $17 \%$ more diverse paradigmatically than its peer topics. 


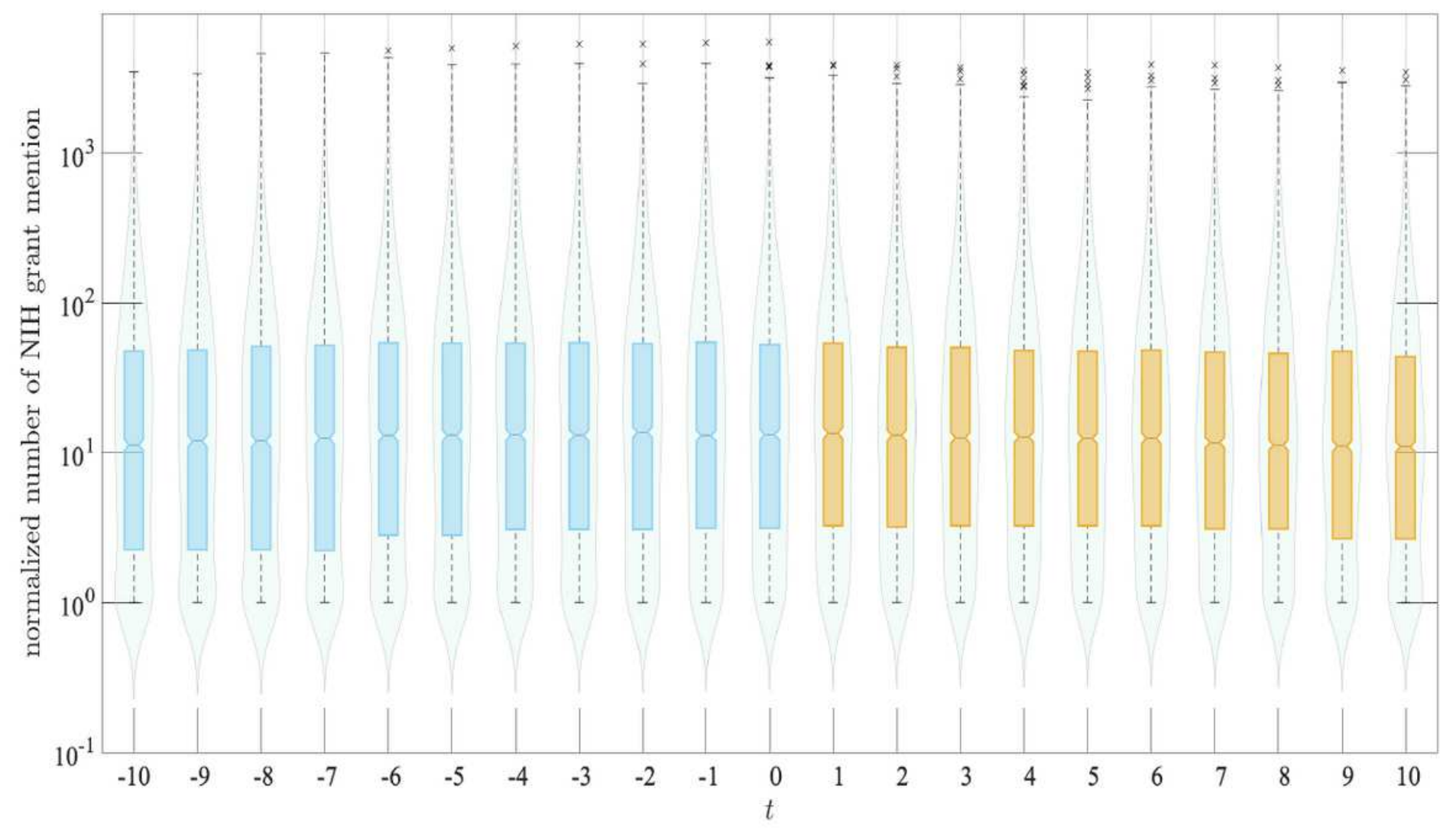

Figure 5

Funding and Revolutionary Growth are Unrelated. Normalized NIH grant funding is flat before and after the prizewinning event, demonstrating that funding levels are unrelated to the extraordinary growth of prizewinning topics. Analysis includes 2,921 prizewinning topics that received at least one NIH funding mention from 1985 to 2005; funding levels are normalized over time by dividing the number of grant mentions by the total number of grants in that year (see SI). The center line of the box plot is the median of the normalized grants, box limits correspond to the data's first and third quartiles, notches represent $95 \% \mathrm{Cl}$, and violin plots represent the data's distribution. 


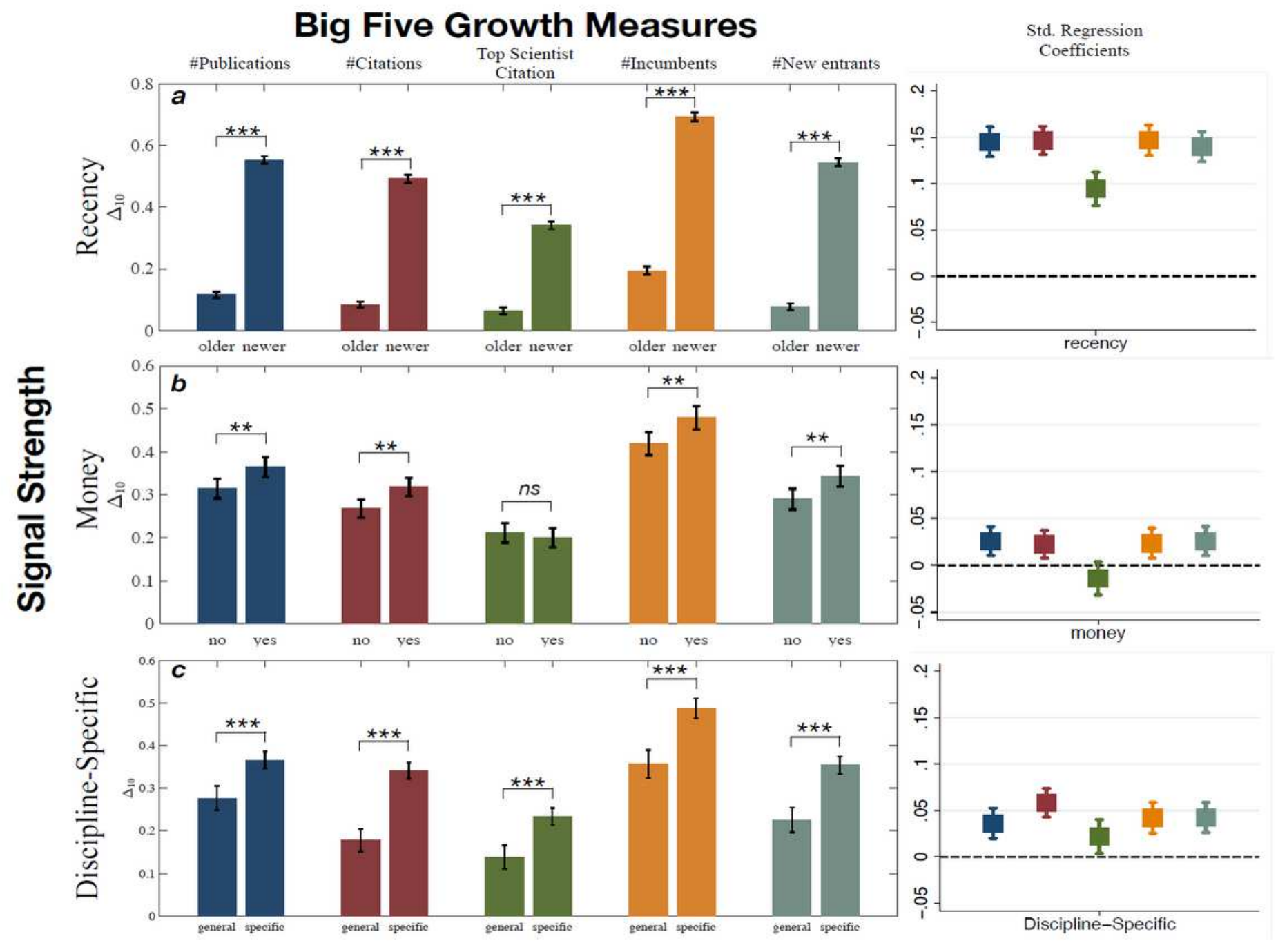

Figure 6

Signal Strength and Revolutionary Growth. Plots (a) through (c) show the ability of a prize's signal strength (measured as recency, money, or specialty) to predict a prizewinning topic's magnitude of unexpected growth $(\Delta \mathrm{t})$ on five growth measures (number of publications, citations, citations by the topic's most-cited scientists, incumbents, and newcomers). Bar plots (with $95 \% \mathrm{Cls}$ ) report the average $\Delta t$ by signal strength predictor. The coefficient plots adjacent to the bar plots show the standardized coefficients from a regression of $\Delta t$ on all signal strength variables; lagged outcome variables at $t=-1,-2$, $-3,-10$; and fixed effects for discipline, prize year, prize age, and number of prize conferrals. The standardized coefficients indicate the relative predictive power of each signal strength variable and the generalizability and robustness of predictions across disciplines and in the presence of potential confounding variables (*** $p<0.001$; ${ }^{* \star} p<0.01$; and $\left.* p<0.05\right)$.

\section{Supplementary Files}

This is a list of supplementary files associated with this preprint. Click to download. 
- SIJinMaUzzi.pdf 